\title{
Fungal, Mycobacterial, and Nocardia infections and the eye: an update
}



\begin{abstract}
Although relatively uncommon, fungi, atypical Mycobacteria, and Nocardia have been isolated from a variety of infections of eye including keratitis, scleritis, canaliculitis, dacryocystitis, endophthalmitis and orbital cellulites. The organisms typically cause a slowly progressive disease. The diseases caused by the organisms can pose both diagnostic and therapeutic challenges. In this manuscript we will describe updates on important aspects of the ocular infections caused by these organisms.

Eye (2012) 26, 245-251; doi:10.1038/eye.2011.332; published online 16 December 2011

Keywords: fungi; non-tubercular Mycobacteria; Nocardia; keratitis; scleritis; endophthalmitis

\section{Introduction}

Infectious diseases of the eye have long been recognized as important causes of blindness. While Chlamydia trachomatis, Neisseria gonorrhoea, and Onchocerca volvulus are important causes of global blindness, ${ }^{1,2}$ many other organisms can cause serious ocular morbidity. Although relatively uncommon, ocular infections caused by fungi, atypical Mycobacteria, and Nocardia can pose both diagnostic and therapeutic challenges. In this manuscript we will describe updates on important aspects of the ocular infections caused by these organisms.
\end{abstract}

\section{Fungal infections of the eye}

Although fungi are recognized as opportunistic pathogens, ocular fungal infections or ophthalmic mycoses are being increasingly recognized as important causes of morbidity and blindness, especially in tropical countries. ${ }^{3-5}$ An overwhelming number of fungal genera and species have been implicated as causes of ophthalmic mycoses, and this number is steadily increasing. Table 1 highlights some of the important genera and species isolated from various ophthalmic mycoses cases.

\section{Keratitis}

Keratitis is by far the most frequent fungal infection of eye. ${ }^{3,4}$ Trauma is the most important predisposing factor. ${ }^{5}$ Other predisposing factors include corneal surgery, prolonged use of corticosteroids or antibiotics, pre-existing ocular diseases, systemic diseases such as diabetes mellitus, and contact lenses. ${ }^{3,4,6,7}$

Fungi produce a slowly progressive disease characterized by localized infiltrate. Classical clinical features are shown in Figures 1a and b.

Although several features are characteristic, not all patients present with these features. Ring infiltrate mimicking acanthamoeba or frank suppuration mimicking bacterial keratitis or dendritic lesions, and even mutton fat endothelial lesions mimicking HSV endothelitis are not uncommon presentations in fungal keratitis. Further, non-fungal microorganisms such as acanthamoeba, nocardia and Grampositive bacteria can present with clinical features resembling fungal infection..$^{8,9}$

Therefore, no clinical feature can be considered absolutely pathognomonic of fungal aetiology. ${ }^{10}$

\section{Challenges with laboratory diagnosis}

Although microscopic examination of smear using various stain and inoculation on culture media helps in identification of fungal infections, laboratory diagnosis can be challenging, especially in patients with deepseated keratitis. In such cases, corneal biopsy helps to establish the diagnosis. ${ }^{11}$ Although this
Cornea and Anterior Segment Services, LV Prasad Eye Institute, Banjara Hills, Hyderabad, India

Correspondence: P Garg, Cornea and Anterior Segment Services, Kallam Anji Reddy Campus, LV Prasad Eye Institute, Banjara Hills,

Hyderabad 500034, India Tel: + 914030612345 ; Fax: + 914023548271

E-mail: prashant@lvpei.org

Received: 10 October 2011 Accepted in revised form: 8 November 2011 Published online: 16 December 2011

This work was presented at the Cambridge Ophthalmological Symposium. 
Table 1 Important fungi isolated from ocular infections

\begin{tabular}{|c|c|c|}
\hline Fungi group & Fungal genus and species & Important ocular diseases \\
\hline \multirow[t]{6}{*}{ Hyaline filamentous } & Fusarium (F. solani, F. dimerum, F. oxysporum) & Keratitis, scleritis, endophthalmitis \\
\hline & Aspergillus (A. fumingatus, A. terrus, A. terreus) & $\begin{array}{l}\text { Keratitis, scleritis, endophthalmitis, oribital cellulitis } \\
\text { Dacryocystitis }\end{array}$ \\
\hline & Scedosporium (S. apiospermum, S. prolificanc) & Keratitis, scleritis, endophthalmitis \\
\hline & & Orbital cellulitis \\
\hline & Paecilomyces (P. lilacinus, P. variotii) & Keratitis, endophthalmitis \\
\hline & Acremonium (A. kilience, A. potronii) & Keratitis, endophthalmitis \\
\hline \multirow[t]{5}{*}{ Dematiaceous } & Bipolaris (B. specifera, B. hawaiiensis) & Keratitis, scleritis \\
\hline & Curvularia (C. lunata, C. geniculata) & Keratitis, scleritis \\
\hline & Exserohilum (E. rostratum) & Keratitis, scleritis \\
\hline & Exophiala (E. dermatitidis) & Keratitis, scleritis \\
\hline & Lasiodiplodia theobromae & Keratitis \\
\hline \multicolumn{3}{|l|}{ Yeasts and zygomycetes } \\
\hline \multirow[t]{2}{*}{ Yeasts } & $\begin{array}{l}\text { Candida (C. albicans, C. parapsilosis, } \\
\text { C.guilliermondii) }\end{array}$ & $\begin{array}{l}\text { Keratitis, infectious crystalline keratopathy, scleritis, } \\
\text { endophthalmitis, orbital cellulitis }\end{array}$ \\
\hline & Cryptococcus (C. neoformans, C. laurentii) & Keratitis, blepharitis, endophthalmitis \\
\hline Zygomycetes & Rhizopus, Mucor, Rhizomucor & Orbital cellulitis, scleritis \\
\hline $\begin{array}{l}\text { Thermally } \\
\text { dimorphic fungi }\end{array}$ & $\begin{array}{l}\text { Paracoccidioides brasiliensis, Blastomyces } \\
\text { dermatitidis, Sporothrix schenckii } \\
\text { Histoplasma capsulatum }\end{array}$ & $\begin{array}{l}\text { Eye lid infection, conjunctivitis, keratitis, } \\
\text { endophthalmitis }\end{array}$ \\
\hline
\end{tabular}

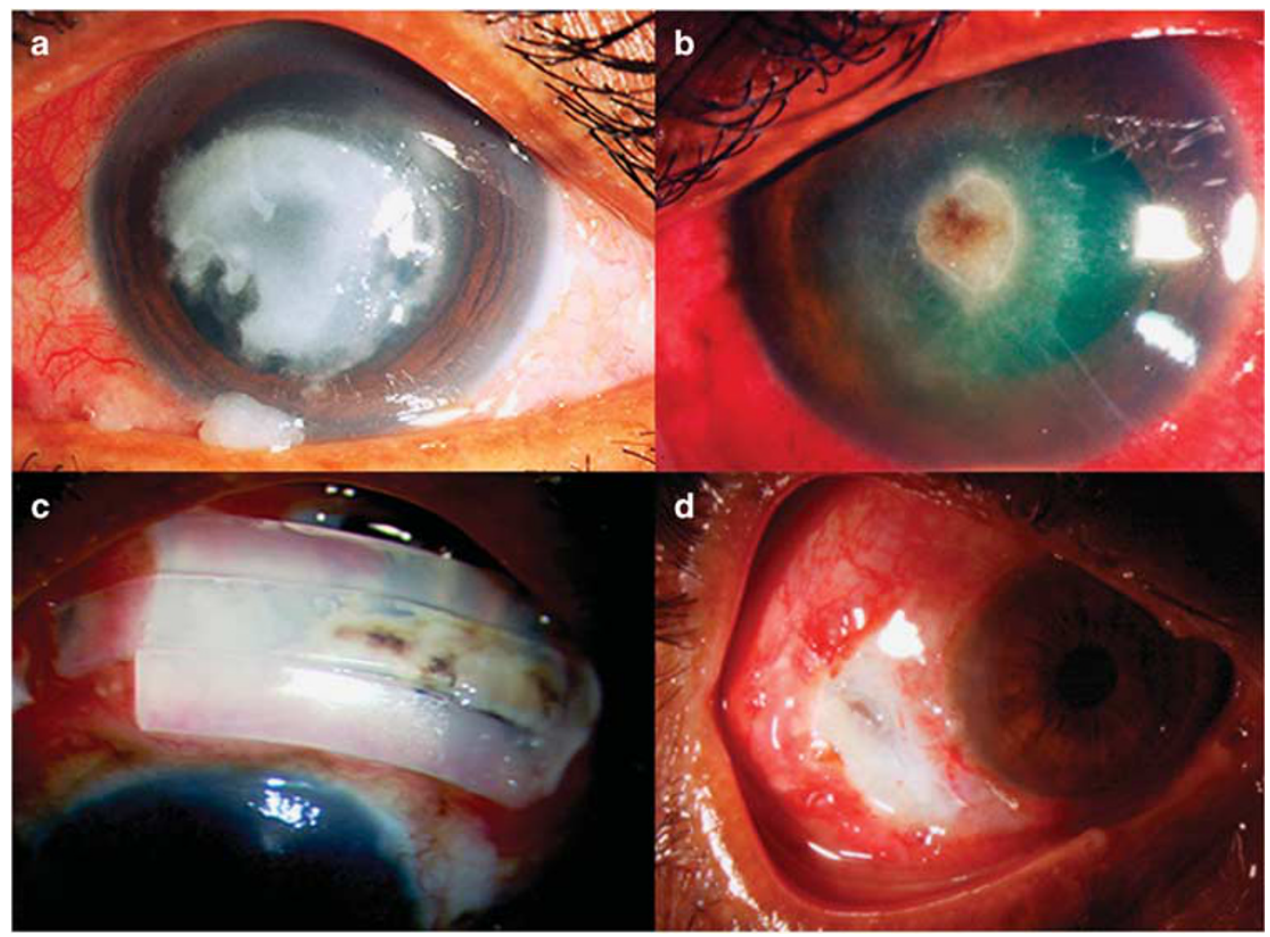

Figure 1 Fungal infections of eye. (a) Shows fungal keratitis with dry gray to dirty white infiltrate and raised edges. (b) Shows keratitis with pigmented infiltrate. (c) Shows pigmented fungal growth on the surface of scleral buckle in a case of fungal scleritis. (d) Shows ulcerated scleritis lesion.

technique allows direct visualization of organisms, it has limitation of being less sensitive, involving tissue destruction and having a high sampling error. Confocal microscopy, a non-invasive, in-vivo technique for examination of cornea, offers an alternative and has been found to be useful in diagnosis of fungal and 
acanthamoeba infections. ${ }^{12}$ However, the technique is not without limitations; besides the cost of the instrument, it is not easy to get good-quality images in painful inflamed eyes, and experience is required for interpretation of images. $^{13,14}$

\section{Therapeutic challenges}

Fungal keratitis cases pose several therapeutic challenges. Only limited numbers of drugs are commercially available for ophthalmic use. Most of the drugs are fungistatic, have limited spectrum of activity, and have poor penetration through ocular structures. Therefore, medical treatment fails to control infection in a significant proportion of cases. ${ }^{15}$ Some of the new molecules investigated in recent past include azoles (voriconazole and posaconazole) and eccinocanidines (caspofungin and micafungin). ${ }^{16,17}$ While the pharmacological properties, in-vitro susceptibility, as well as the anecdotal reports suggest superiority of voriconazole over other antifungal agents, ${ }^{16}$ a randomized clinical trail in South India comparing natamycin with voriconazole in treatment of mycotic keratitis did not find any difference in the scar size, visual acuity, and perforation rate. ${ }^{18}$ Therefore, more clinical trials are required to provide rigorous evidence basis to guide using these molecules.

Can we increase drug concentration at the site of infection? As penetration into ocular tissues is a major limiting factor, attempts have been made to push the antifungal drugs directly into the site of infection. The group from the Bascom Palmer Eye Institute (BPEI) used iontophoresis to deliver amphotericin B into the corneal stroma. ${ }^{19}$ More recently, clinicians have tried intrastromal injection of water-soluble molecules such as amphotericin B and voriconazole. Sharma et $a l^{20}$ published a case series demonstrating the successful use of this technique in the management of recalcitrant keratitis. However, another approach worth exploring will be the use of nanotechnology. As the technology allows regulated release of drugs, it prolongs the antifungal activity.

\section{Surgical treatment}

Lessons learnt from understanding of distribution of fungal filaments in corneal tissues can help us improve the management of fungal keratitis. In two separate studies, we found that fungal filaments can be located entirely into anterior stroma (39\%), especially in patients with plaque-like infiltrate, ${ }^{21,22}$ and superficial keratectomy will help in management by reducing the fungal load in such cases.

Xie $e t \mathrm{al}^{23}$ published successful management of fungal keratitis by deep anterior lamellar keratoplasty in a large series of cases. However, we need to exercise caution in patients with advanced keratitis, as fungal filaments were found to penetrate Descemet's membrane in $61.5 \%$ specimens from advanced keratitis cases (unpublished data).

Although penetrating keratoplasty seems to be a better option in patients with deep keratitis, the procedure is associated with several challenges. ${ }^{24}$ It is not surprising that $35 \%$ of the keratoplasty procedures performed for active fungal keratitis fail within the first month and $50 \%$ by the end of first year. ${ }^{25}$

\section{Scleritis}

Fungi are important aetiological agents of infective scleritis in tropical regions. ${ }^{26,27}$ In a report published by us, $38 \%$ cases of infective scleritis were caused by fungi. ${ }^{26}$ The fungal infection of sclera commonly occurs following accidental trauma or following variety of surgical procedures, but can also occur as an extension from cornea or choroid and rarely as an endogenous infection. ${ }^{27}$

Fungal scleritis usually presents as slowly progressive scleral necrosis with suppuration. Figures $1 \mathrm{c}$ and $\mathrm{d}$ document various features of fungal scleritis.

The diagnosis of fungal scleritis is often delayed because the disease in initial stage appears identical to that caused by immune-mediated disease. Further, as the organisms lie deep in the stroma, negative microbiology is not rare in these cases. The outcome of medical therapy alone is usually poor due to poor penetration of topical and systemic antifungal agents into avascular sclera.

It is therefore important to:

- Consider infective aetiology in differential diagnosis of all cases of suppurative scleritis, especially if there is history of accidental or surgical trauma or debilitating systemic disease.

- Remember that the negative microbiology does not rule out infection. Such cases should be subjected to scleral biopsy.

- Combine medical management with surgical intervention involving excision of overlying conjunctiva, Tenon's capsule and necrotic sclera, and debridement of the ulcer base.

- Continue antifungal treatment for a long time after clinical resolution to take care of viable fungi that can still be found in tissues after presumed cure.

- Remove buckling elements and sutures along with thorough debridement of any white deposits from underlying sclera and irrigation with $5 \%$ povidone iodine in patients with buckle infection.

\section{Endophthalmitis}

Fungi have been isolated from cases of both exogenous and endogenous endophthalmitis. ${ }^{28-31}$ Similar to keratitis 
and scleritis, fungal endophthalmitis poses diagnostic and therapeutic challenges. Although classically described to have longer latency compared with bacterial infection, many reports on fungal endophthalmitis have described infection developing within 4 days of inoculation..$^{30,31}$ The clinical picture is variable, and depending on the virulence can resemble bacterial endophthalmitis. The variable presentation coupled with lack of clinical suspicion results in delayed diagnosis in many cases. To avoid this, ophthalmologists should consider fungal aetiology in post-trauma or post-cataract surgery infections in geographic areas where fungal infections are common.

Another important aspect in diagnosis of endophthalmitis is submitting appropriate sample for microbiology. Traditionally, vitreous aspirate is believed to be more sensitive than an anterior chamber aspirate. In the study from BPEI, six cases with positive anterior chamber aspirate results had negative vitreous culture results. ${ }^{31}$ This was attributed to the primary location of the infection. Furthermore, some fungi may be less capable of penetrating the vitreous cavity. Therefore, whenever possible, both anterior chamber and vitreous aspirates should be submitted for a complete endophthalmitis evaluation.

The management of fungal endophthalmitis primarily comprises of vitrectomy and intravitreal injection of antifungal drugs. Traditionally, amphotericin B has been the preferred antifungal agent for intraocular injection. More recently, the use of voriconazole is gaining popularity. ${ }^{31}$ Intracameral injection of antifungal agents can be considered when the intraocular infection primarily involves the anterior chamber. One must also remember that patients with fungal endophthalmitis often require multiple intraocular injections. However, there are no definitive protocols to guide repeat injections, and more studies are needed to determine the optimal antifungal regimen.

\section{Atypical mycobacteria and the eye}

Atypical mycobacteria, also known as nontuberculous mycobacteria (NTM), are aerobic, non-motile, non-spore forming bacilli, and have been isolated from a wide variety of ocular infections including keratitis, scleritis, canaliculitis, dacryocystitis, orbital cellulitis, uveitis, and endophthalmitis. ${ }^{32-35}$ The vast majority of ocular infections are caused by the Runyon group IV organisms $M$. fortuitum, and M. chelonae. The other less common organisms include $M$. sulzi, M. flavescens, M. avium-intracellulare, M. gordonae, and M. marinum. ${ }^{36-38}$

Keratitis remains the most common ocular infection of NTMs. ${ }^{32,33}$ On the basis of the experience with the
35 cases managed at the LV Prasad Eye Institute and by review of the literature, it is evident that trauma and the metallic corneal foreign body in particular are the most common predisposing factors. The infection has also been reported following a variety of surgical procedures including cataract and refractive surgery. ${ }^{39-42}$

One of the characteristic features of NTM keratitis is the delay in the onset of clinical disease after corneal trauma. The disease presents with a broad spectrum of clinical features including cracked windshield appearance, ring infiltrate, satellite lesions, and infectious crystalline keratopathy. In our series, all patients presented with central or paracentral localized infiltrate extending for a variable depth of stroma (Figure 2).

Although there was no case in the series published by us, ${ }^{28}$ NTMs have been isolated from few cases of scleritis. ${ }^{34,38}$ The clinical picture in NTM scleritis is indistinguishable from fungal infection.

NTMs have also been isolated from both endogenous ${ }^{35,43}$ and exogenous endophthalmitis cases including postoperative endophthalmitis. ${ }^{38,44-46}$ The most characteristic sign of NTM endophthalmitis following cataract surgery is multiple white plaques between intraocular lens and posterior capsule or on the anterior hyaloid face mimicking P. acne endophthalmitis.

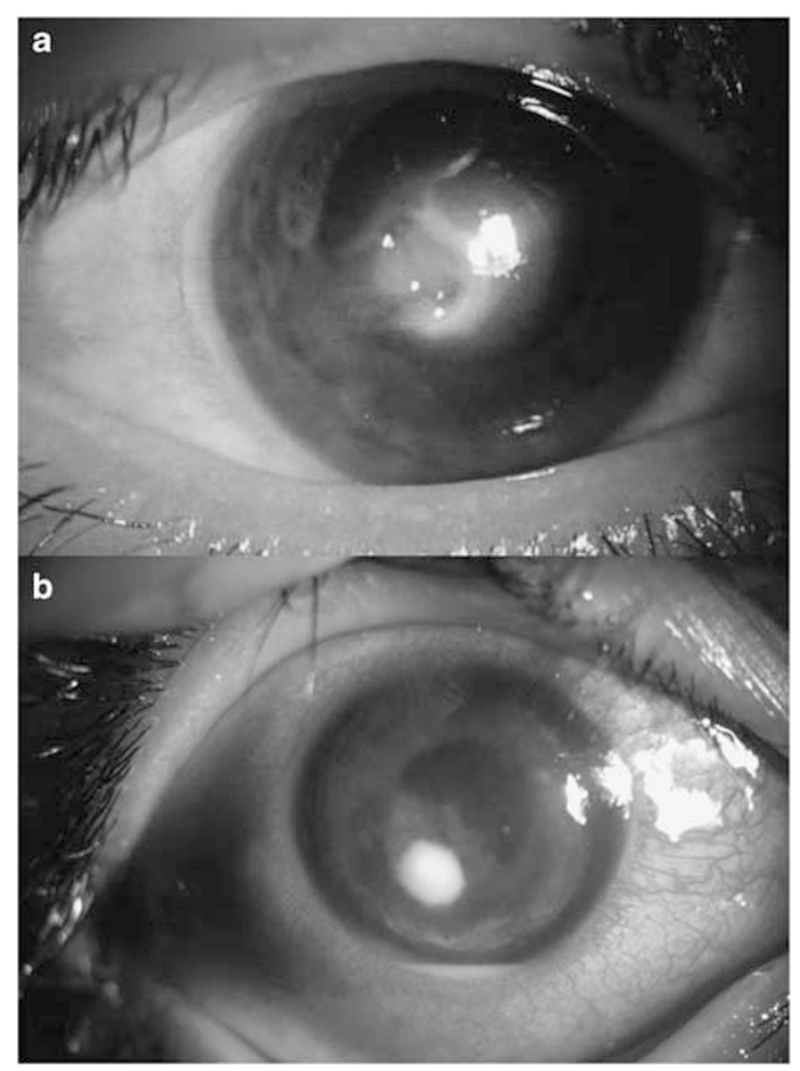

Figure 2 Non-tubercular mycobacteria keratitis after accidental trauma (a) and laser in-situ keratomileusis (b). 
The diagnosis of NTM infection poses several challenges. The diagnosis is often delayed primarily because it being rare, the clinicians do not consider it in differential diagnosis. The clinical picture mimics the infections caused by other low-virulent bacteria and fungi. Further, the organisms stain poorly on routine screening dyes or are seen as partially stained bacilli. ${ }^{47}$ Furthermore, although the members of Runyon group IV produce positive cultures within 7 days, the infection caused by slow growers is likely to be missed on routine microbiology as culture plates are often discarded after 7 days. Therefore, the diagnosis of NTM infection depends to a large extent on the clinicians' vigilance. In all the suspected cases, they should order specific stains such as the Ziehl-Neelsen acid fast stain and culture on specific media such as the Lowenstein-Jensen media.

Treatment of NTM ocular infections is also challenging. In vitro antimicrobial susceptibility studies uniformly suggest amikacin clarithromycin and azithromycin to be the best drugs in its management. There is an interest in the use of fluoroquinolones, both for prophylaxis and treatment. The results of susceptibility test including minimum inhibitory concentrations show that fluoroquinolones, including the fourth-generation ones, are unlikely to be useful for this infection. ${ }^{48}$ Despite the use of sensitive antibiotics, several patients of NTM infection do not respond to medical treatment and require surgical intervention.

\section{Nocardia and the eye}

Nocardia organisms and mycobacteria belong to the same bacterial order Actinomycetales; they exhibit similarities with respect to cell wall antigens and bacteriophage susceptibility. These are, however, differentiated by staining characteristics, morphology, and the lipid composition of cell wall. Although the organisms are known to cause pulmonary infections in immunocompromised individuals, these are also identified as rare but important cause of ocular infections.

Various infections caused by these organisms include-keratitis, ${ }^{9}$ scleritis, ${ }^{9,26}$ conjunctivitis, canaliculitis, dacryocystitis, orbital cellulitis, and endophthalmitis. ${ }^{9}$

Corneal infection is by far the most common ocular infection caused by Nocardia and is reported after accidental and surgical trauma including refractive surgery. $9,49,50$ The clinical picture is characterized by a relatively slow and recalcitrant keratitis with mean time to presentation $24.5 \pm 22.2$ days in our series. Figure 3 shows various corneal pictures of this infection. Patchy anterior stromal infiltrates with yellow-white pin-head-sized raised calcareous lesions arranged in a wreath pattern is the most characteristic feature of this infection. However, this classical clinical picture is not seen in post-surgery infections and in advanced

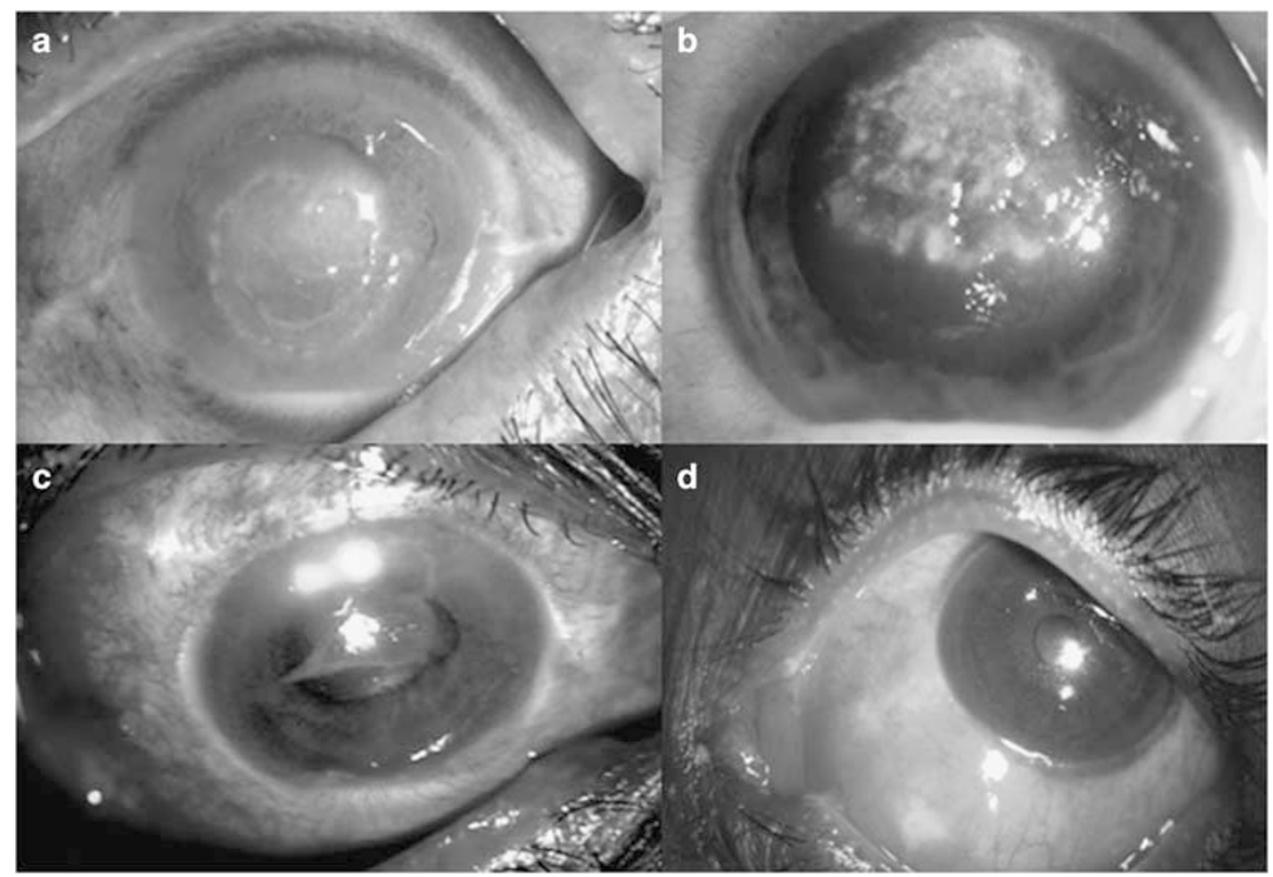

Figure 3 Nocardia infections of eye. (a) Shows nocardia keratitis with characteristic wreath-like lesion. (b) Shows a case of advanced keratitis with dry-looking infiltrate mimicking fungal infection. (c) Shows nocardia keratitis with suppurative lesion. (d) Shows suppurative nodular scleritis. 
keratitis cases. Nocardia are the second most common cause of infectious scleritis in Southern India. ${ }^{26}$ The predisposing factors and clinical picture of Nocardia scleritis are almost similar to that of fungal and NTM scleritis.

Nocardia are isolated from cases of both exogenous and endogenous endophthalmitis., ${ }^{9,51}$ A large number of these cases are reported from South India. ${ }^{9,51,52}$ Similar to keratitis and scleritis, the organism produces a slow insidious disease; the mean time to presentation from symptom onset was $21.5 \pm 20.6$ days and the mean duration from surgery to presentation was $47.5 \pm 49.4$ days in our series. ${ }^{9}$ The clinical picture is characterized by distinctive anterior chamber findings such as the exudates on corneal endothelium or nodule-like deposits at the pupillary border in significant number of patients. These intense anterior segment findings are coupled with minimal vitritis or posterior segment findings. ${ }^{9,51,52}$ Cases with advanced endophthalmitis present with white fluffy exudates on posterior capsule and anterior vitreous mimicking fungal endophthalmitis. The clinical presentation in endogenous endophthalmitis is much different than exogenous endophthalmitis and is characterized by large choroidal lesions with overlying haemorrhages.

In contrast to NTM, the diagnosis of Nocardia infection of cornea is usually straightforward. In our series, the diagnosis was suspected in $45 \%$ patients at the first visit, based on the characteristic corneal infiltrate. In contrast, nocardia scleritis and endophthalmitis resembles closely with fungal and NTM infections. Even in these cases, microscopic examination of ocular specimen using Gram stain as well as $1 \%$ acid-fast stain $(81.1 \%$ of cases in our series) facilitates early diagnosis. The organisms are not fastidious and grow on routine culture media, although bit slowly.

While identification of organism to the genus level is easy, speciation is often difficult using standard microbiology protocols. We subjected 19 isolates identified as Nocardia species on routine biochemical tests to identification by gene sequencing of $16 \mathrm{~S}$ rRNA gene. We identified eight isolates that have never been reported in ocular infections. ${ }^{53}$ On the basis of this experience, we concluded that time has come when we should use molecule methods for the precise identification of microorganisms.

\section{Treatment}

The Nocardia organisms show a good susceptibility to amikacin and sulphonamides. ${ }^{53,54}$ Other aminoglycosides such as gentamicin and tobramycin are the next best options in the treatment of this infection. The susceptibility to fluoroquinolones is variable. Although keratitis and scleritis cases respond very well to amikacin therapy, the outcome of endophthalmitis management is not encouraging.

\section{Conclusion}

Fungi, atypical Mycobacteria, and Nocardia are rare but important causes of ocular infections. The infection caused by these organisms poses several diagnostic and therapeutic challenges. A high degree of clinical suspicion, with appropriate diagnostic tests will help early diagnosis and institution of appropriate therapy.

\section{Conflict of interest}

The authors declare no conflict of interest.

\section{References}

1 Thylefors B, Negrel AD, Pararajasegaram R, Dadzie KY. Global data on blindness. Bull WHO 1995; 73: 115-121.

2 Congdon NG, Friedman DS, Lietman T. Important causes of visual impairment in the world today. JAMA 2003; 290: 2057-2060.

3 Thomas PA. Current perspectives on ophthalmic mycoses. Clin Microbiol Rev 2003; 16: 730-797.

4 Kalkanci A, Ozdek S. Ocular fungal infections. Curr Eye Res 2011; 36: 179-189.

5 Gopinathan U, Sharma S, Garg P, Rao GN. Review of epidemiological features, microbiological diagnosis and treatment outcome of microbial keratitis: experience of over a decade. Indian J Ophthalmol 2009; 57: 273-279.

6 Gopinathan U, Garg P, Fernandes M, Sharma S, Athmnathan S, Rao GN. The epidemiological features and laboratory results of fungal keratitis: a 10-year review. Cornea 2002; 21: 555-559.

7 Khor W, Aung T, Saw S, Wong T, Tambyah PA, Tan AL et al. An outbreak of Fusarium keratitis associated with contact lens wear in Singapore. JAMA 2006; 295: 2867-2873.

8 Sahu SK, Das S, Sharma S, Vemuganti GK. Acanthamoeba keratitis presenting as a plaque. Cornea 2008; 27: 1066-1067.

9 Decroos FC, Garg P, Reddy AK, Sharma A, Krishnaiah S, Mungale $M$ et al. Hyderabad Endophthalmitis Research Group. Optimizing diagnosis and management of nocardia keratitis, scleritis, and endophthalmitis: 11-year microbial and clinical overview. Ophthalmology 2011; 118: 1193-1200.

10 Thomas PA, Leck AK, Myatt M. Characteristic clinical features as an aid to the diagnosis of suppurative keratitis caused by filamentous fungi. Br J Ophthalmol 2005; 89: 1554-1558.

11 Alexandrakis G, Haimovici R, Miller D, Alfonso EC. Corneal biopsy in the management of progressive microbial keratitis. Am J Ophthalmol 2000; 129: 571-576.

12 Kaufman SC, Musch DC, Belin MW, Cohen EJ, Meisler DM, Reinhart WJ et al. Confocal microscopy: a report by the American Academy of Ophthalmology. Ophthalmology 2004; 111: 396-406.

13 Hau SC, Dart JKG, Vesaluoma M, Parmar DN, Claerhout I, Bibi K et al. Diagnostic accuracy of microbial keratitis with in vivo scanning laser confocal microscopy. Br J Ophthalmol 2010; 94: 982-987.

14 Garg P. Diagnosis of microbial keratitis. Br J Ophthalmol 2010; 94: 961-962.

15 Lalitha P, Prajna NV, Kabra A, Mahadevan K, Srinivasan M. Risk factors for treatment outcome in fungal keratitis. Ophthalmology 2006; 113: 526-530.

16 Hariprasad SM, Mieler WF, Lin TK, Sponsel WE, Graybill JR. Voriconazole in the treatment of fungal eye infections: a 
review of current literature. $\mathrm{Br} J$ Ophthalmol 2008; 92: 871-878.

17 Hurtado-Sarrió M, Duch-Samper A, Cisneros-Lanuza A, Díaz-Llopis M, Peman-Garcíia J, Vazquez-Polo A. Successful topical application of caspofungin in the treatment of fungal keratitis refractory to voriconazole. Arch Ophthalmol 2010; 128: 941-942.

18 Prajna NV, Mascarenhas J, Krishnan T, Reddy PR, Prajna L, Srinivasan $\mathrm{M}$ et al. Comparison of natamycin and voriconazole for the treatment of fungal keratitis. Arch Ophthalmol 2010; 128: 672-678.

19 Yoo SH, Dursun D, Dubovy S, Miller D, Alfonso E, Forster RK et al. Lontophoresis for the treatment of paecilomyces keratitis. Cornea 2002; 21: 131-132.

20 Sharma N, Agarwal P, Sinha R, Titiyal JS, Velpandian T, Vajpayee RB. Evaluation of intrastromal voriconazole injection in recalcitrant deep fungal keratitis: case series. Br J Ophthalmol 2011; 95: 1735-1737.

21 Vemuganti GK, Garg P, Gopinathan U, Naduvilath TJ, Buddi R, Rao GN. Evaluation of agent and host factors in progression of mycotic ketatitis: a histological and microbiological study of 167 corneal buttons. Ophthalmology 2002; 109: 1538-1546.

22 Garg P, Vemuganti GK, Chaterjee S, Gopinathan U, Rao GN Pigmented plaque presentation of dematiaceous fungal keratitis: a clinicopathologic correlation. Cornea 2004; 23: 571-576.

23 Xie L, Zhai H, Shi W, Zhao J, Sun S, Zang X. Hyphal growth pattern and recurrence of fungal keratitis after lamellar keratoplasty. Ophthalmology 2008; 115: 983-987.

24 Sharma N, Sachdev R, Jhanji V, Titiyal JS, Vajpayee RB. Therapeutic keratoplasty for microbial keratitis. Curr Opin Ophthalmol 2010; 21: 293-300.

25 Chen WL, Wu CY, Hu FR, Wang IJ. Therapeutic penetrating keratoplasty for microbial keratitis in Taiwan from 1987 to 2001. Am J Ophthalmol 2004; 137: 736-743.

26 Jain V, Garg P, Sharma S. Microbial scleritis-experience from a developing country. Eye 2009; 23: 255-261.

27 Alfonso EC, Forster RK, Garg P, Sharma S. Fungal infections. In: Foster CS, Azar DT, Dohlman CH (eds). Smolin and Thoft's The Cornea: Scientific Foundations and Clinical Practice, 4th ed. Lippincott Williams \& Wilkins: Philadelphia, 2005, pp 405-425.

28 Montan P. Endophthalmitis. Curr Opin Ophthalmol 2001; 12 75-81.

29 Smith SR, Kroll AJ, Lou PL, Ryan EA. Endogenous bacterial and fungal endophthalmitis. Int Ophthalmol Clin 2007; 47: 173-183.

30 Chakrabarti A, Shivaprakash MR, Singh R, Tarai B, George VK, Fomda BA et al. Fungal endophthalmitis: fourteen years experience from a center in India. Retina 2008; 28: 1400-1407.

31 Wykoff CC, Flynn Jr HW, Miller D, Scott IU, Alfonso EC. Exogenous fungal endophthalmitis: microbiology and clinical outcomes. Ophthalmology 2008; 115: 1501-1507, 1507.e1-2.

32 Huang SCM, Soong HK, Chang JS, Liang YS. Non tuberculosis mycobacterial keratitis: a study of 22 cases. Br J Ophthalmol 1996; 80: 962-968.

33 Lalitha P, Rathinam SR, Srinivasan M. Ocular infections due to non-tuberculous mycobacteria. Indian J Med Microbiol 2004; 22: 231-237.

34 Rich RM, Smiddy WE, Davis JL. Infectious scleritis after retinal surgery. Am J Ophthalmol 2008; 145: 695-699.

35 Matieli LCV, Freitas DE, Sampaio J, Moraes NSB, Zorat MC, Halfling-Lima AL. Mycobacterium abscessus endopthalmitis: treatment dilemma and review of literature. Retina 2006; 26 : 826-830.

36 Moore MB, Newton C, Kaufman HE. Chronic keratitis caused by Mycobacterium gordonae. Am J Ophthalmol 1986; 102: 516-552.

37 Knapp A, Stern GA, Hood CI. Mycobacterium aviumintracellulare corneal ulcer. Cornea 1987; 6: 175-180.

38 Schonherr U, Naumann GOH, Lang GK, Bialasiewicz AA. Sclerokeratitis caused by Mycobacterium marinum. Am J Ophthalmol 1989; 108: 607-608.

39 Matoba AY, Torres J, Wilhelmus KR, Hamill MB, Jones DB. Bacterial keratitis after radial keratotomy. Ophthalmology 1989; 96: 1171-1175.

40 Jain V, Garg P, Sharma S, Vemuganti GK. Suture-less wound infection by unusual acid-fast organisms. Cornea 2008; 27: 615-618.

41 Garg P, Chaurasia S, Vaddavalli PK, Muralidhar R, Mittal V, Gopinathan U. Microbial keratitis after LASIK. J Refract Surg 2010; 26: 209-216.

42 Srinivasan M, Prajana L, Prajana V. A cluster of cases of Mycobacterium chelonae keratitis following penetrating keratoplasty. Indian J Ophthalmol 2005; 53: 67-68.

43 Ambler JS, Meisler DM, Zakov ZN, Hall GS, Spech TJ. Endogenous Mycobacterium chelonae endophthalmitis. Am J Ophthalmol 1989; 108: 338-339.

44 Ramaswamy AA, Biswas J, Bhaskar V, Gopal L, Rajagopal R, Madhavan HN. Postoperative Mycobacterium chelonae endophthalmitis after extracapsular cataract extraction and posterior chamber intraocular lens implantation. Ophthalmology 2000; 107: 1283-1286.

45 Benz MS, Murray TG, Dubovy SR, Katz RS, Eifrig CW. Endophthalmitis caused by mycobacterium chelonae abscessus after intravitreal injection of triamcinolone. Arch Ophthalmol 2003; 121: 271-273.

46 Gedde SJ, Scott IU, Tabandeh H, Luu KK, Budenz DL, Greenfield DS et al. Late endophthalmitis associated with glaucoma drainage implants. Ophthalmology 2001; 108: 1323-1327.

47 Garg P, Athmanathan S, Rao GN. Mycobacterium Chelonei masquerading as Corynebacterium in a case of infectious keratitis: a diagnostic dilemma. Cornea 1998; 17: 230-232.

48 Reddy AK, Garg P, Babu KH, Gopinathan U, Sharma S. In vitro antibiotic susceptibility of rapidly growing nontuberculous mycobacteria isolated from patients with microbial keratitis. Curr Eye Res 2010; 35: 225-229.

49 Bharathi MJ, Ramakrishnan R, Vasu S, Meenakshi R, Chirayath A, Palaniappan R. Nocardia asteroides keratitis in South India. Indian J Med Microbiol 2003; 21: 31-36.

50 Garg P, Chaurasia S, Vaddavalli PK, Muralidhar R, Mittal V, Gopinathan U. Microbial keratitis after LASIK. J Refract Surg 2010; 26: 209-216.

51 Ramakrishnan R, Bharathi MJ, Shivkumar C, Mittal S, Meenakshi R, Khadeer MA et al. Microbiological profile of culture-proven cases of exogenous and endogenous endophthalmitis: a 10-year retrospective study. Eye (Lond) 2009; 23: 945-956.

52 Lalitha P, Rajagopalan J, Prakash K, Ramasamy K, Prajna NV, Srinivasan M. Postcataract endophthalmitis in South India incidence and outcome. Ophthalmology 2005; 112: 1884-1889.

53 Reddy AK, Garg P, Kaur I. Speciation and susceptibility of Nocardia isolated from ocular Infections. Clin Microbiol Infect 2010; 16: 1168-1171.

54 Lalitha P, Tiwari M, Prajna NV, Gilpin C, Prakash K, Srinivasan M. Nocardia keratitis: species, drug sensitivities, and clinical correlation. Cornea 2007; 26: 255-259. 